\title{
転炉吹錬制御システムの開発*
}

\author{
岩村＼cjkstart健**·古澤 正夫***.宮本 正和**·布袋屋道則***・橘＼cjkstart秀文****
}

\section{Development of BOF blowing control system*}

\author{
Ken Iwamura, Masao Furusawa, Masakazu Miyamoto, Michinori Hoterya \\ and Hidefumi TACHIBANA
}

In the No. 2 Steel making plant at Kashima Steel Works, CC-DC(Continuous Casting Direct Charge) process has been adopted to realize the synchronized operation between a caster (3CC) and a hot strip mill. In order to take advantage of this process, the BOF (Basic Oxygen Furnace) operation has been required to hit exact end-point carbon contents and metal bath temperatures, and to shorten the refining time. In addition, steel quality depends largely on the end-point hitting ratio. To meet the requirements, we have developed a new endpoint control system of BOF since the renewal of a process computer in 1992.

After the adoption of the new system, the direct tapping ratio is about $70 \%$, which results in the reduction of operational cost and the improvement of productivity.

\section{1. 緒言}

転炬製鋼法の導入以来，転炉プロセスの最大の課題の ひとつは吹錬終点における温度と成分の的中であり，そ のために転炉吹錬制御において，さまざまな技術が開発 されてきた.とくに，溶鋼温度・成分を吹錬中に直接計測 し，その計測值に基づいて終点制御を行うというサブラ ンス情報（溶鋼温度・C 濃度）を用いた終点制御システ ムは鉄鋼各社で導入され転炉プロセスの機能向上に寄与 してきた1)。

鹿島第 2 製鋼工場では，1982 年に，サブランスを用い た終点制御システムを構築している2).しかしながら，操 業条件の変化などの理由で終点制御システムの中核であ るダイナミックモデルの精度を長期に渡って維持できな

* 原稿受付 1995 年 12 月 26 日

** 住友金属工業（株） システムエンジニアリング事業部 Sumitomo Metal Industries, Ltd.; 8 1-chome Fusocho, Amagasaki city, Hyogo 660, JAPAN

*** 住友金属工業（株）鹿島製鉄所 Sumitomo Metal Industries, Ltd.; 3 Hikari Kashima-gun Ibaragi 314, JAPAN

**** 住金制御エンジニアリング（株） 九州事業所 Sumitomo Metal Industries Control \& Engineering Corp.; 1 Konomi-machi, Kourakita ward, Kitakyushu city, Fukuoka 802, JAPAN

Key Words: endpoint control, BOF, automatic blowing, reblow ratio, direct tapping ratio.
いという問題があった. 近年では各社で, 溶銑予備処理 技術の発達 (特に溶銑脱燐技術)により, 転炉吹錬での脱 燐機能を除去しスラグレス化を図り転炉吹錬の操業を安 定化させ, 終点制御の制御性を向上させかつ機能を拡張 させる試みがなされているが3)-5), 本研究では, より高 精度なモデル開発を通じて上記問題の解決をめざした。

そこで，ダイナミックモデルおよびフィードバックモデ ルのレベルアップを実施し, 終点制御システムの積極的 活用, すなわち終点制御の自動化を推進した結果, 再吹 錬率低下などの成果をあげることができた，以下終点制 御モデルの概要と終点制御システムの実機適用結果につ いて述べる.

\section{2. 設備概要}

鹿島第 2 製鋼工場の概要を Fig. 1 に示す.

連続鋳造は熱延と直結しており (CC-DCprocess; Continuous Casting Direct Charge process), このプロセス の利点を活用するためには, 転炉では, 正確に目標溶鋼 温度・成分になるように溶銑を吹鍊し，かつ，より短時間 で連続鋳造へ溶鋼を供給する必要がある。 


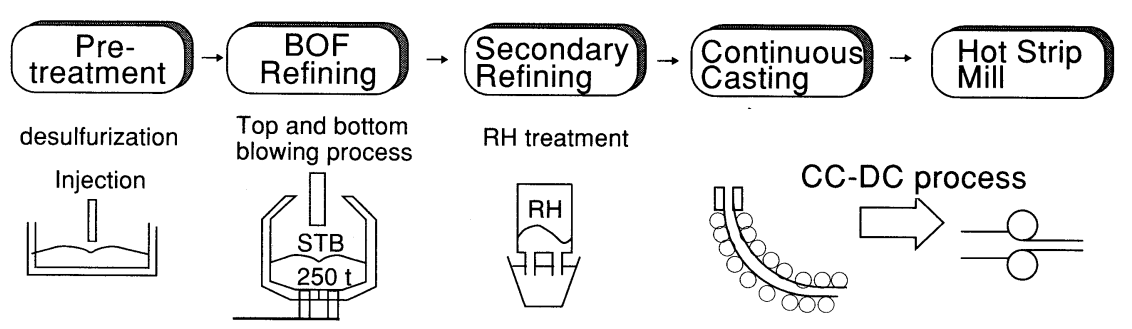

Fig. 1. Material flow in No. 2 steel making plant at Kashima Steel Works

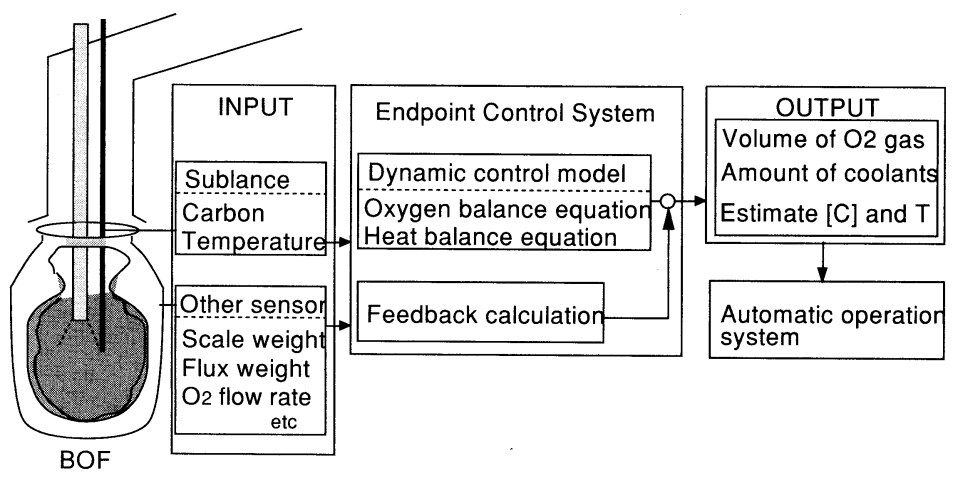

Fig. 2 Concept of endpoint control system

\section{3. 終点制御システムの概要}

\section{1 システム概要}

Fig. 2 には, 終点制御システムの概要を示す。吹錬途 中での溶鋼温度・C 濃度を計測させるサブランス測定装 置, 上吹き酸素流量・底吹きガス流量や冷却材投入量等の 操業条件の計測装置および, ダイナミックモデル・フィー ドバックモデルにより構築されている.

ダイナミックモデルは温度バランス式・酸素バランス式 からなり，溶鋼温度・ C 濃度を推定する.フィードバック モデルはダイナミックモデルの補正のために導入されて おり, 今回大幅な改善を実施した.

本システムの機能は, 終点目標温度・ $\mathrm{C}$ 濃度を満足す るために必要な酸素量および冷却材量（鉄鉱石・スケー ル）を指示し，また，自動吹錬終了（オートストップ）実 施時には, 自動的に酸素の吹込みを終了し, 吹錬を終え ることにある。

\section{4. 終点制御システムの詳細}

\section{1 ダイナミックモデル}

ダイナミックモデルは溶鋼 $\mathrm{C}$ 濃度を推定する酸素バラ ンス式と溶鋼温度を推定する温度バランス式から構成さ れている. 雨式を連立させて, 操作量である酸素量と冷
却材量を算出する.酸素バランス式は式 (1)で表され, 低 $\mathrm{C}$ 領域から高 $\mathrm{C}$ 領域までの $\mathrm{C}$ 濃度と酸素消費量の関係を 包括的に定式化している5).

$$
\begin{aligned}
& \frac{F_{O 2}+\eta \Sigma W_{s u b} \cdot O_{2}}{W_{S T}} \\
& =a_{0}\left(C_{S L}-C_{E P}\right)+a_{1} \ln \frac{C_{S L}}{C_{E P}}+a 2 \\
& \quad+\Sigma l_{i}\left(X_{i}-\bar{X}_{i}\right)+F B_{C}
\end{aligned}
$$

ただし

$a_{0}, a_{1} a_{2}:$ 酸素バランス式の係数

$C_{S L}$ ： サブランス計測時の溶鋼 C 濃度 [wt\%]

$C_{E P}$ ： 終点 C 濃度 [wt\%]

$F_{O 2}$ ： サブランス計測時点から吹錬終点までの 酸素消費量 $\left[\mathrm{Nm}^{3}\right]$

$\eta ： \quad$ 副原料持込み酸素効率

$W_{\text {sub }}$ ：副原料投入量 $[\mathrm{t}]$

$\mathrm{O}_{2}:$ 副原料中の酸素含有率 $\left[\mathrm{Nm}^{3} / \mathrm{t}\right]$

$W_{S T}$ : 溶鋼重量 $[\mathrm{t}]$

$l_{i}: \quad$ 操業要因の係数

$X_{i}: \quad$ 操業条件要因

$F B_{c} ： \quad$ フィードバック補正項 $\left[\mathrm{Nm}^{3} / \mathrm{t}\right]$ 
Table 1 The rule of the feedback calculation model $F B(i)$ : feedback value, Mdlerro(i) : error of the model erro(i) : error of feedback model

$G_{F B}$ : feedback gain, $H$ : minimum detectable value

\begin{tabular}{|c|c|c|}
\hline case & the trend of the error of the model & the amount of feedback \\
\hline \multirow{2}{*}{1} & \multirow{2}{*}{ Mdlerro $(i-l) \cdot$ Mdlerro $(i) \geq 0$} & $F B(i)=F B(i-l)+G_{F B} \cdot\left(\frac{\operatorname{erro}(i)+\operatorname{erro}(i-l)}{2}\right)$ \\
\hline & & $F D(\imath)-F D(\imath-\imath)+G F_{B}$ \\
\hline 2 & $\begin{array}{c}\text { Mdlerro }(i-l) \cdot M d \text { derro }(i)<0 \\
\text { and } \\
|\operatorname{erro}(i)|-|\operatorname{erro}(i-l)|>H\end{array}$ & $F B(i)=F B(i-l)+G_{F B} \cdot \operatorname{erro}(i)$ \\
\hline 3 & $\begin{array}{c}\text { Mdlerro }(i-l) \cdot M d \text { derro }(i)<0 \\
\text { and } \\
|\operatorname{erro}(i)|-|\operatorname{erro}(i-l)| \leq H\end{array}$ & $F B(i)=F B(i-l)$ \\
\hline
\end{tabular}

である．その吹錬で必要な酸素量 (左辺) が, C 濃度の 変化量をベースとする要因の多重回帰式で表されている. $X i$ は各種操業条件を表しており, 上吹き酸素流量, スラ グ量等で構成している。また, 右辺には, フィードバック モデルによる補正項を追加している。

温度バランス式も, 従来の式では酸素バランス式と同 様に C 濃度の変化量のベースとする要因の多重回帰式で あったが，鹿島製鉄所第 2 製鋼工場のような低炭主体の 操業では, 終点 $\mathrm{C}$ 濃度の変動が小さく, その昇温量との 関係が不明確なために, 安定した精度を得ることができ なかった．そこで, C 濃度ベースの形から, より昇温量 との相関のある積算酸素量ベースの形に変更することに より，溶鋼温度の推定精度を向上させることができた6). (2) 式に温度バランスを示すが, 左辺の昇温量を積算酸素 量と操業要因で表す多重回帰式になっている．操業条件 $X i$ は (1) 式で用いたものと同じである.また, 酸素バラ ンス式と同様に, フィードバックモデルの補正項を右辺に 追加している.

$$
\begin{aligned}
& T_{E P}-T_{S L} \\
& \quad=b_{0} \frac{F_{O 2}+\eta \Sigma W_{s u b} \cdot O_{2}}{W_{S T}}+b_{2} \\
& \quad+\gamma \Sigma W_{s u b} \cdot T_{s u b}+\Sigma l_{i}\left(X_{i}-\bar{X}_{i}\right)+F B_{T}
\end{aligned}
$$

ただし

$T_{S L} ： \quad$ サブランス計測時点の溶鋼温度 $\left[{ }^{\circ} \mathrm{C}\right]$

$T_{E P}$ ： 終点時の溶鋼温度 $\left[{ }^{\circ} \mathrm{C}\right]$

$b_{0}, b_{2}$ : 温度バランス式の係数

$\gamma:$ 冷却剂の冷却効率

$l_{i}: \quad$ 操業要因の係数

$T_{s u b}$ : 副原料の冷却量 $\left[{ }^{\circ} \mathrm{C} / t\right]$

$\mathrm{FB}_{T}$ ：フィードバック補正項 $\left[{ }^{\circ} \mathrm{C}\right]$

とする。

\section{2 フィードバックモデル}

フィードバックモデルはダイナミックモデルの推定誤 差を補償するために導入している.フィードバック量は, (1)，(2)式に示したようにダイナミックモデルの補正項と して用いる. 終点にて温度・C 濃度を測定したチャージの ダイナミックモデルの推定䛊差の傾向を考慮してフィード バック量を計算する. Table 1 にその計算方法を示すが, 大きく 3 パターンに分類してフィードバック量を算出し ている.

また, 酸素バランス式では, Table 1 の方法に従って計 算したフィードバック量を, ダイナミックモデルの始点と なるサブランス測定時 $\mathrm{C}$ 濃度および終点目標 $\mathrm{C}$ 濃度を用 いて補正している．Fig. 3 に示すように，吹き込んだ酸 素量に対する終点 $\mathrm{C}$ 濃度はサブランス測定時 $\mathrm{C}$ 濃度レベ ルによって大きく異なるが，このサブランス測定時 $\mathrm{C}$ 濃 度は各チャージごとに違うため, フィードバック量もこの 情報をもとに補正する必要があるからである，以下，そ の補正方法を説明する.

まず, Fig. 3 の酸素吹き込み量と終点 $\mathrm{C}$ 濃度の関係を 動浴 C 濃度レベルごとに定式化する（(3) 式）.今回は, 三つの領域に分けている.

$$
C_{E P}=s_{1} \cdot \log \left(\frac{\Delta O_{2}}{W_{S T}}\right)+s_{2}
$$

ただし

$s_{1}, s_{2}:$ 係数

$\Delta \mathrm{O}_{2}:$ 酸素量 $\left[\mathrm{Nm}^{3}\right]$

である.そして, 終点 $\mathrm{C}$ 濃度に対する吹き込み酸素量の 感度を，(3) 式を終点 C 濃度で微分した (4) 式で表す.

$$
\varepsilon=\frac{d \Delta O_{2}}{d C_{E P}}=\frac{W_{S T}}{s_{1}} \cdot e\left(\frac{C_{E P}-s_{2}}{s_{1}}\right)
$$

ただし

$\varepsilon: \quad$ 感度

とする。 


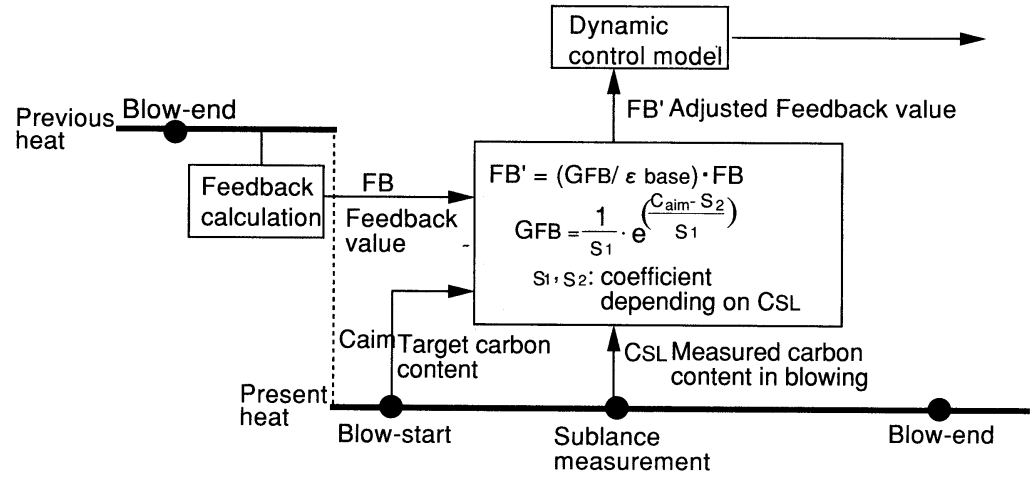

Fig. 4 Adjustment of feedback value in blowing
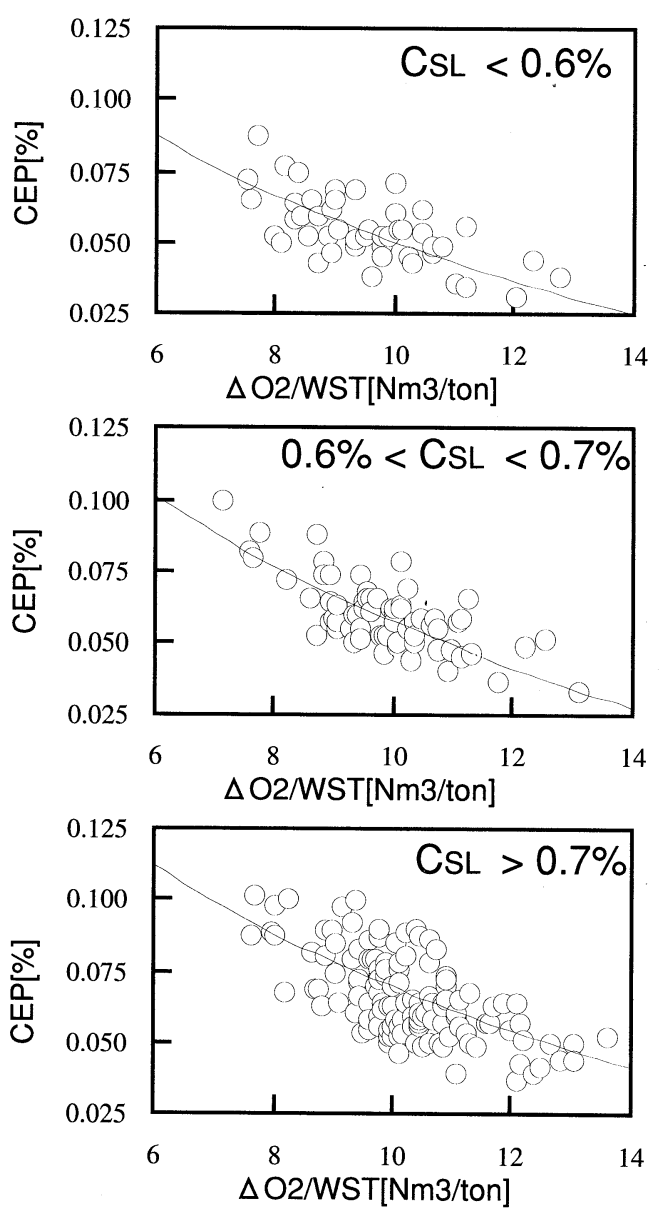

Fig. 3 The relationship between the carbon content and the amount of oxygen
つぎに，動浴測定時の $\mathrm{C}$ 濃度が属する領域のパラメー 夕および終点目標 C 濃度 (Caim) を用いて感度を計算し ((7) 式), 基準感度 $\left(\varepsilon_{\text {base }}\right)$ との比である補正感度 $(\mathbf{h})$ を用いて, (5) 式のように, フィードバック值を補正する. Fig. 4 には, フィードバック計算のフローを示す.

$$
F B^{\prime}(i)=h \cdot F B(i)
$$

ただし

$$
\begin{aligned}
h & =\frac{\varepsilon^{\prime}}{\varepsilon_{\text {base }}} \\
\varepsilon^{\prime} & =\frac{d \Delta O_{2}}{d C_{E P}}=\frac{W_{S T}}{s_{1}} \cdot e\left(\frac{C_{a i m}-s_{2}}{s_{1}}\right)
\end{aligned}
$$

である、

さらに, 上記の一連のフィードバック計算を, 吹錬特性 の大きく異なる 3 種類の鋼種ごとに設定している.

近年では, 終点 $\mathrm{C}$ 測定を省略して出鋼するダイレクト タップが各社で実施されているが, ダイレクトタップが 実施される場合, ダイナミックモデルの推定誤差を計算 するフィードバックの機能が働かなくなり, ダイナミック モデルの精度低下につながる.しかし (3) (7) 式の補正 を動浴測定時に行うことにより,ダイレクトタップが実施 されても適切なフィードバック量を毎チャージ設定可能と なった。

\section{3 エキスパートシステムの活用}

終点制御システムは, 先にも述べたようように，吹錬 途中でのサブランスによる動浴測定が起点となるが, こ の動浴測定タイミングを設定するのが，スタティックモ デルである3). スタティックモデルの機能としては, その ほかに，吹鍊中に投入するフラックス量を決定する機能 がある。

このスタティックモデルは, 特に転炉操業時での非定 常作業（例えば炉底交換など）が実施された場合に，精 
Table 2 Example of adjustments based on operater's know-how

\begin{tabular}{|l|c|c|}
\hline \multirow{2}{*}{ Factor } & \multicolumn{2}{c|}{ Adjustments } \\
\cline { 2 - 3 } & Oxygen & Heat \\
\hline First heat of the new furnace & $+1.0 \mathrm{Nm}^{3} / p t$ & $-80^{\circ} \mathrm{C}$ \\
\hline Bottom exchange & $+4.0 \mathrm{Nm}^{3} / p t$ & $-40^{\circ} \mathrm{C}$ \\
\hline Gunning repair of refractry & - & $-10^{\circ} \mathrm{C}$ \\
\hline Addition of steel adhesion on the mouth & - & $-3.3^{\circ} \mathrm{C} /$ ton \\
\hline Wating time & - & $-8.0^{\circ} \mathrm{C} /$ ton \\
\hline
\end{tabular}

度が低下し, その結果, 動浴測定時の溶鋼温度· C 濃度 のバラッキが大きくなり終点制御に悪影響を及ぼしてし まうという問題があった.

そこで, 非定常作業に対するオペレータのノウハウを もとにエキスパートシステムを構築し，スタティックモ デルを補正し, 動浴測定時の溶鋼温度・C 濃度を安定化 した (Fig. 5). Table 2 には，その補正ロジック例を示す.

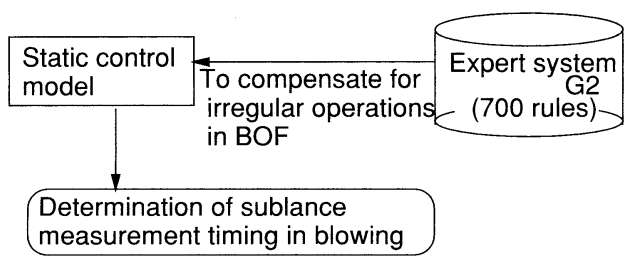

Fig. 5 Function of the expert system

\section{5. 適用結果}

Fig. 6 には，一炉代に渡るダイナミックモデルの的中率 の推移を示す.ダイミナックモデルおよびフィードバック モデルのレベルアップなどの一連の取り組みにより，ダイ ナミックモデルのパラメー夕調整を実施しなくても，一 炉代に渡って精度良く推定可能となった。

そこで，本終点制御システムを実機に適用し，吹錬自 動終了（オートストップ）を推進した．Fig. 7 には，溶 鋼温度・ $\mathrm{C}$ 濃度の終点目標値と終点実績値との関係を示 すが，オートストップ実施時のほうがオペレータ判断に よる手動の吹錬終了時より，目標值に対して精度良好で ある。

そして，従来はオペレータの判断による吹錬終了が 100\%実施されていたが，オートストップの適用率は $70 \%$ まで上昇した (Fig. 8).

さらに, 終点測定を省略して出鋼するダイレクトタップ の比率も上昇し, Table 3 に示すように再吹錬率の低下. 処理時間の短縮等の吹錬諸元を改善することができた。
Table 3 Effect of the new system

\begin{tabular}{|l|c|c|}
\hline & Conventioal & New \\
\hline Direct tapping ratio & $49.9 \%$ & $65.2 \%$ \\
\hline Reblowing ratio & $4.0 \%$ & $2.0 \%$ \\
\hline Wating time for tapping & $1.21 \mathrm{~min}$. & $0.95 \mathrm{~min}$. \\
\hline
\end{tabular}

\section{6. 結言}

主にモデルのレベルアップを実施した終点制御システ ムを実機に適用し，その終点制御の自動化を推進した。そ の結果, 普通銑による転炉吹錬としては高いオートストッ プ適用率を達成し，吹錬諸元の改善に貢献した。

今後は, 溶鋼温度・C 濃度だけでなく, 鋼の特性に大き な影響を持つ $\mathrm{P}$ 濃度や $\mathrm{Mn}$ 濃度の制御も含めた終点制御 システムの構築を図ってゆく.

\section{参考文献}

1) 島：転炉技術の展開と今後の展望; 鉄と鋼, Vol. 76, No. 11 pp. 1765-1769 (1990)

2) 高輪, 片山, 布袋屋, 平山：転炉複合吹錬終点制御モデルの 開発; 鉄と鋼, Vol. 73, No. 7, pp. 836-843 (1987)

3) 佐藤：高純度鋼溶製のための溶銑予備処理·転炉技術; 最近の 高純度鋼溶製技術の進歩, 日本鉄鋼協会, pp. 73-105 (1992)

4) 金本, 岡島, 山根, 山内：転炉吹鍊におけるりん・マンガン 制御技術の現状と今後の方向；鉄と鋼, Vol. 76, No. 11, pp. 1964-1971 (1990)

5) 斉藤, 坪根, 東, 山根, 竹添：転炉自動吹錬技術の開発；鉄 と鋼, Vol. 76, No. 11, pp. 1972-1977 (1990)

6) 谷, 岩村, 橘, 古澤, 宮本: 転炉制御モデルの開発; 材料と プロセス, Vol. 6, p. 1069 (1993) 


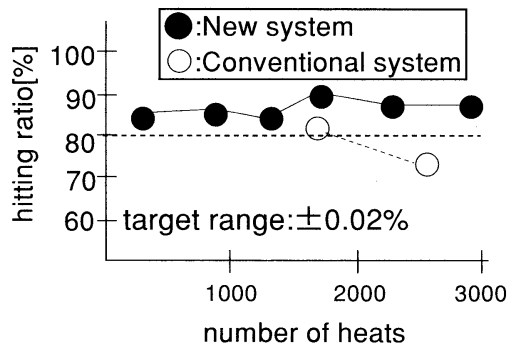

(a) Carbon content at endpoint

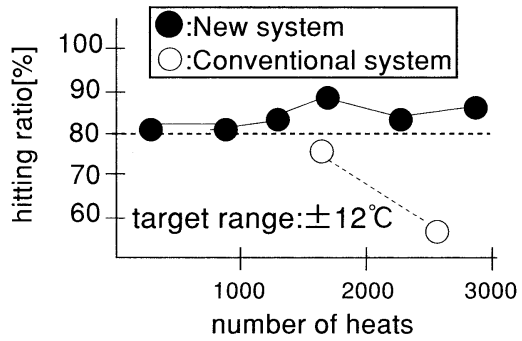

(b) Temperature at endpoint

Fig. 6 Estimation accuracy of dynamic control model

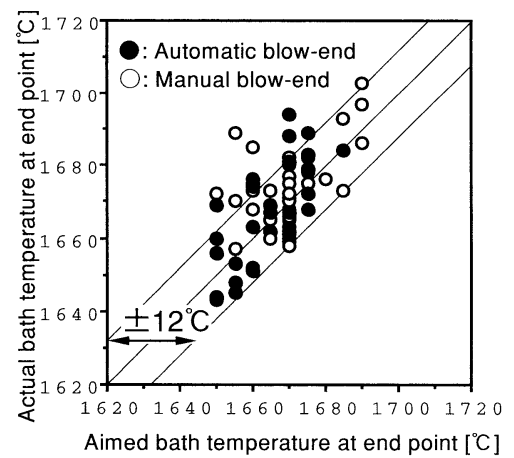

(a) Bath temperature at end point

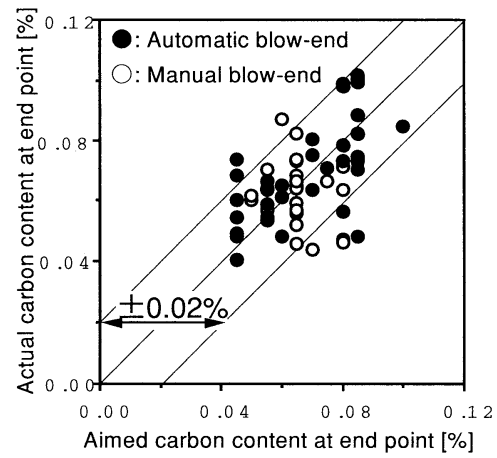

(b) Carbon content at end point

Fig. 7 Accuracy of Auto stop mode

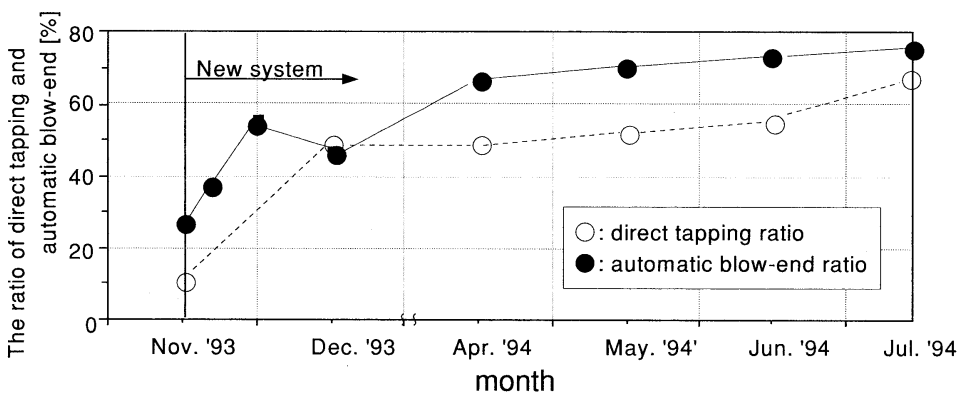

Fig. 8 The change of the direct tapping ratio and automatic blow-end ratio 
